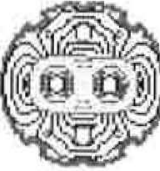

\title{
THE LHC CRYOMAGNET SUPPORTS IN GLASSFIBER REINFORCED EPOXY: \\ A LARGE SCALE INDUSTRIAL PRODUCTION WITH HIGH REPRODUCIBILITY IN PERFORMANCE
}

\author{
A. Poncet', M.Struik', J. Trigo ${ }^{2}$, and V. Parma ${ }^{1}$
}

\begin{abstract}
The about 1700 LHC main ring super-conducting magnets are supported within their cryostats on 4700 low heat in leak column-type supports. The supports were designed to ensure a precise and stable positioning of the heavy dipole and quadrupole magnets while keeping thermal conduction heat loads within budget. A trade-off between mechanical and thermal properties, as well as cost considerations, led to the choice of glass fibre reinforced epoxy (GFRE). Resin Transfer Moulding (RTM), featuring a high level of automation and control, was the manufacturing process retained to ensure the reproducibility of the performance of the supports throughout the large production. The Spanish aerospace company EADS-CASA Espacio developed the specific RTM process, and produced the total quantity of supports between 2001 and 2004. This paper describes the development and the production of the supports, and presents the production experience and the achieved performance.
\end{abstract}

I CERN, European Organization for Nuclear Research, Geneva, Switzerland 2 EADS, CASA-Espacio, Madrid, Spain

Presented at the 2007 Cryogenic Engineering Conference and International Cryogenic Materials Conference CEC-ICMC2007

16-20 July 2007, Chattanooga, USA

\footnotetext{
CERN

CH - 1211 Geneva 23

Switzerland
} 


\title{
THE LHC CRYOMAGNET SUPPORTS IN GLASS- FIBER REINFORCED EPOXY: A LARGE SCALE INDUSTRIAL PRODUCTION WITH HIGH REPRODUCIBILITY IN PERFORMANCE
}

\author{
A. Poncet ${ }^{1}$, M.Struik ${ }^{1}$, J. Trigo ${ }^{2}$, and V. Parma ${ }^{1}$ \\ ${ }^{1}$ CERN, European Organization for Nuclear Research \\ Geneva, CH-1211, Switzerland. \\ ${ }^{2}$ EADS, CASA-Espacio, \\ Madrid, Av. Aragon 28022, Spain.
}

\begin{abstract}
The about 1700 LHC main ring super-conducting magnets are supported within their cryostats on 4700 low heat in leak column-type supports. The supports were designed to ensure a precise and stable positioning of the heavy dipole and quadrupole magnets while keeping thermal conduction heat loads within budget. A trade-off between mechanical and thermal properties, as well as cost considerations, led to the choice of glass fibre reinforced epoxy (GFRE). Resin Transfer Moulding (RTM), featuring a high level of automation and control, was the manufacturing process retained to ensure the reproducibility of the performance of the supports throughout the large production.

The Spanish aerospace company EADS-CASA Espacio developed the specific RTM process, and produced the total quantity of supports between 2001 and 2004.

This paper describes the development and the production of the supports, and presents the production experience and the achieved performance.
\end{abstract}

KEYWORDS: cryogenics, LHC, composite materials fabrication.

PACS: 07.20.Mc, 81.05.Mh, Ni, Pj, Qk,

\section{INTRODUCTION}

The accurate and stable positioning of the LHC super-conducting magnets within their cryostats (Table 1) is the primary requirement for which the support posts have been designed. Their mechanical properties allow reproducible alignment of the cold mass housing the magnets when, via external jacks, the entire cryo-magnet is displaced with 
TABLE 1. Main requirements for the LHC support posts

\begin{tabular}{lll}
\hline \multicolumn{1}{c}{ Requirement } & \multicolumn{1}{c}{ Cryo-dipole } & \multicolumn{1}{c}{ Short Straight Section } \\
Positioning accuracy: & & \\
X (radial) & $\pm 1 \mathrm{~mm}$ & $\pm 0.5 \mathrm{~mm}$ \\
Y (longitudinal) & $\pm 2 \mathrm{~mm}$ & $\pm 1 \mathrm{~mm}$ \\
$Z$ (vertical) & $\pm 1 \mathrm{~mm}$ & $\pm 0.5 \mathrm{~mm}$ \\
Positioning reproducibility-stability: (in operation, during lifetime) & \\
X (radial) & $< \pm 0.3 \mathrm{~mm}(3 \sigma)$ & $< \pm 0.3 \mathrm{~mm}(3 \sigma)$ \\
Y (longitudinal) & $< \pm 1 \mathrm{~mm}(3 \sigma)$ & $< \pm 1 \mathrm{~mm}(3 \sigma)$ \\
$Z$ (vertical) & $< \pm 0.3 \mathrm{~mm}(3 \sigma)$ & $< \pm 0.3 \mathrm{~mm}(3 \sigma)$ \\
Achieved thermal performance & & \\
$1.9 \mathrm{~K}$ level & $49 \mathrm{~mW}$ & $47 \mathrm{~mW}$ \\
$4.5-20 \mathrm{~K}$ level & $450 \mathrm{~mW}$ & $420 \mathrm{~mW}$ \\
$50-75 \mathrm{~K}$ level & $7.1 \mathrm{~W}$ & $7.2 \mathrm{~W}$ \\
\hline
\end{tabular}

reference to cryostat-mounted fiducials [1].

Accurate positioning of the cold mass within the cryostats is achieved through the relatively tight dimensional tolerances of the vacuum vessels and a close-fit assembly (H7/g6) at the interface with the support posts. The close-fits, together with full circumferential bolting at the interface, ensures positional stability, except for the sliding support posts where the transverse position of the cold mass with respect to the fiducials relies on a close-fit (H7/g6) sliding slot/key interface between support posts and vacuum vessel. The dimensional accuracy of the support posts is also essential, and requires a final precision of the order of $0.1 \mathrm{~mm}$ in the functional dimensions, obtained by final machining. An overall accuracy of $1.02 \mathrm{~mm}(\mathrm{rms})$ and $0.98 \mathrm{~mm}(\mathrm{rms})$ in the vertical and horizontal planes respectively were measured on the entire population of 360 main quadrupoles [2].

The positional stability of the magnets is determined by the design of the supports and the choice of the material [3]. The supports were designed to provide a minimum guaranteed stiffness to minimise cold mass movements due to unknown external loads (mainly interconnects forces and transversal weight components from the LHC tunnel inclination). Stringent cryogenic requirements imposed the use of low thermal conductivity-to-stiffness ratio materials. Coping with long-term stability (limited creep) further restricted the choice of materials and imposed a minimally stressed design (<35 MPa in compression).

The selected material was Glass Fibre Reinforced Epoxy resin (GFRE), using long E glass-fibre fabric and a DGEBA epoxy resin system. The composite part was to be in one part with integrated flanges, and cured in a single stage; gluing of composite parts or assembly by other techniques was explicitly forbidden. Machining of the composite
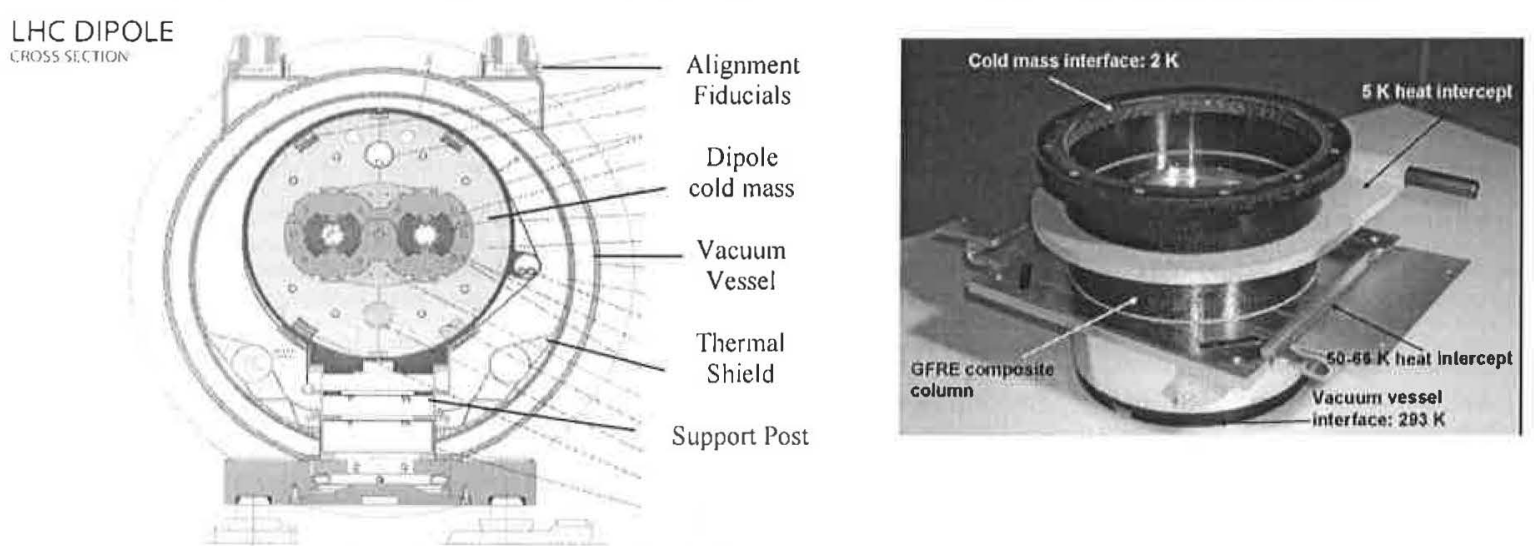

FIGURE 1. Cross-section of an LHC cryo-dipole (left), and a support post (right). 
part was also restricted to a minimum not to undermine its mechanical integrity.

CERN defined the overall design of the supports posts, including geometry and interfaces; it also specified the mechanical and thermal performance requirements and defined the main guidelines of the quality assurance plan and qualification tests. A high reproducibility in performance throughout the production of some 4700 units was sought, in particular for the mechanical stiffness of the composite part, thus restricting the choice to high-quality and robust design manufacturing processes under a strict quality assurance. Following a competitive tender in European industry, EADS-CASA Espacio, a company specialized in composite structures for aerospace applications, was selected.

The company was in charge of making the manufacturing design and of producing the entire quantity of support posts. The composite structure was designed to fulfil the mechanical requirements. The selection of the composite material constituents (epoxy system, and glass-fibre fabrics), the design of the lay-up, the choice of the manufacturing process and the associated quality assurance plan, were left to the expertise of the manufacturer.

Resin Transfer Moulding (RTM) was the proposed manufacturing method, being suitable to a large-scale industrial production of high quality components. This technique presents the major advantage of being highly automated and less sensitive to the skill of labour as compared to other processes like pre-preg moulding, thus reducing production costs while guaranteeing reproducible quality.

\section{THE COMPOSITE COLUMN}

The composite columns are made of a main 4 mm-thick tubular composite part, with integrated flanges formed as a result of the stacking sequence in the lay-up and are obtained in a single RTM process.

The composite material and the lay-up were selected to achieve the specified mechanical stiffness while satisfying thermal conductivity constraints.

\section{Thermal Conductivity of the Composite Material}

Considering the large experience acquired by CERN through thermal measurements on prototype supports [3], the characterization of the thermal conductivity of the materia] for the mass production was limited to a thermal conductivity check at $15 \mathrm{~K}$.

Measurements were made at the CERN cryogenic laboratory on a sample (4 $\mathrm{mm} \times 8 \mathrm{~mm} \times$ $35 \mathrm{~mm}$ ) cut out of a plate of the same material proposed for the mass production, in the direction intended to be the vertical axis of the support posts. This test was carried out based on the standard ASTM C-518-98, but with some adaptation for cryogenic temperatures, using calibrated heat-meters [4]. A thermal conductivity lower than $160 \mathrm{~mW} \mathrm{~K}^{-1} \mathrm{~m}^{-1}$ at $15 \mathrm{~K}$ was specified (as average measured value when the temperature difference between the sample extremities does not exceed $20 \mathrm{~K}$ ), and a value of $148 \pm 7$ $\mathrm{mW} \mathrm{K} \mathrm{K}^{-1}$ was measured, thus validating the choice of the material.

\section{Mechanical Characterization of the Composite Material}

A preliminary characterisation on samples was made by EADS CASA. Tensile and flexural tests were performed at room temperature, according to ISO 527 and ISO 14125 , to measure the elastic properties of the material and evaluate rupture limits (Tables 2 and 3 ) for the design of composite column. 
TABLE 2. Tensile testing results on 5 samples at room temperature.

\begin{tabular}{cccc}
\hline & $\begin{array}{c}\text { Rm } \\
(\mathbf{M P a})\end{array}$ & $\begin{array}{c}\text { E modulus } \\
(\mathbf{G P a})\end{array}$ \\
\hline Average & $\mathbf{4 0 4 . 6}$ & Average & $\mathbf{2 1 . 8}$ \\
\hline Min. (sample 3) & 380 & Min. (samples 2,3) & 21 \\
Max. (sample 2) & 419 & Max. (sample 1) & 23 \\
\hline
\end{tabular}

TABLE 3. Flexural testing results on 5 samples at room temperature.

\begin{tabular}{cc}
\hline & $\begin{array}{c}\text { Rm } \\
(\mathbf{M P a})\end{array}$ \\
\hline Average & $\mathbf{6 5 1}$ \\
\hline Min. (sample 2) & 619 \\
Max. (sample 5) & 681 \\
\hline
\end{tabular}

A second more detailed testing campaign was then conducted at ARC Seibersdorf research (Austria) to characterise the mechanical properties at cryogenic temperature. Tensile tests on samples taken along the longitudinal and transversal axis of the support column were first repeated at room temperature (RT), and then conducted at $77 \mathrm{~K}$ and at $4.2 \mathrm{~K}$. The results are reported in Tables 4 and 5 .

A higher tensile strength at RT was observed in this $2^{\text {nd }}$ campaign, probably due to an improved preparation of the samples. With respect to the values at $293 \mathrm{~K}$, an increase of $24 \%$ in the tensile strength is observed at $77 \mathrm{~K}$ on the longitudinal samples, but an increase of only $8 \%$ at $4.2 \mathrm{~K}$. A similar but less pronounced behaviour is seen on the transversal samples. For all tests, the dispersion on sample results remains within $10 \%$.

\section{Composite Material Constituents and Lay-Up}

The aim in the design of the composite columns was to achieve a compression stiffness of at least $17 \mathrm{GPa}$, and keeping the achieved value within $\pm 5 \%$ throughout the entire production of support posts.

The lay-up of the composite column was chosen to be symmetric and balanced. Two different E-glass dry fabrics were used: tri-axial and bi-axial braids. The tri-axial braid is tubular, having a diameter of $232 \mathrm{~mm}$, with $51 \%$ of fibre volume at $0^{\circ}$ (the axis of the column) and $49 \%$ at $\pm 45^{\circ}$, having a mass per area of $1199 \mathrm{~g} / \mathrm{m}^{2}$ (Figure 2, left). The biaxial braid is tubular, having a diameter of $19.1 \mathrm{~mm}$, with fibres at $\pm 45^{\circ}$, having a mass per area of $1041 \mathrm{~g} / \mathrm{m}^{2}$. Both braids were supplied by $A \& P$ Technology. The walls of the column are made out of four layers of tri-axial braid. The braids are bent inward and outwards to form the lower and upper flanges respectively. The increase in thickness of the flanges is obtained by interposing layers of bi-axial braid (Figure 2, right).

The epoxy resin system adopted is 823RTM, with a cure cycle of $1 \mathrm{~h}$ dwell at $125{ }^{\circ} \mathrm{C}$, supplied by Cytec-Fiberite. A dark die (1\% in overall resin weight) Araldite AW137 supplied by $C I B A$, which gives a characteristic black colour to the composite material, is added for better visual control of the resin flow during the RTM process.

TABLE 4. Tensile testing on 5 longitudinal samples, at $293 \mathrm{~K}, 77 \mathrm{~K}$, and $4.2 \mathrm{~K}$.

\begin{tabular}{cccccc}
\hline Test at & $\mathrm{Rm}$ & Test at & $\mathrm{Rm}$ & Test at & $\mathrm{Rm}$ \\
$293 \mathrm{~K}$ & $(\mathrm{MPa})$ & $77 \mathrm{~K}$ & $(\mathrm{MPa})$ & $4.2 \mathrm{~K}$ & $(\mathrm{MPa})$ \\
\hline Average & $\mathbf{4 5 9 . 3}$ & Average & $\mathbf{5 7 0 . 4}$ & Average & $\mathbf{4 9 6 . 7}$ \\
Min. & 436.6 & Min. & 535.0 & Min. & 441.2 \\
Max. & 485.1 & Max. & 586.0 & Max. & 519.5 \\
\hline
\end{tabular}

TABLE 5. Tensile testing on 5 transversal samples, at $293 \mathrm{~K}, 77 \mathrm{~K}$, and $4 \mathrm{~K}$.

\begin{tabular}{cccccc}
\hline Test at & $\mathrm{Rm}$ & Test at & $\mathrm{Rm}$ & Test at & $\mathrm{Rm}$ \\
$293 \mathrm{~K}$ & $(\mathrm{MPa})$ & $77 \mathrm{~K}$ & $(\mathrm{MPa})$ & $4.2 \mathrm{~K}$ & $(\mathrm{MPa})$ \\
\hline Average & $\mathbf{7 9 . 0}$ & Average & $\mathbf{8 3 . 8}$ & Average & $\mathbf{8 0 . 3}$ \\
Min. & 73.0 & Min. & $\mathbf{7 9 . 8}$ & Min. & 75.7 \\
Max. & 86.5 & Max. & 88.0 & Max. & $\mathbf{8 2 . 6}$ \\
\hline
\end{tabular}



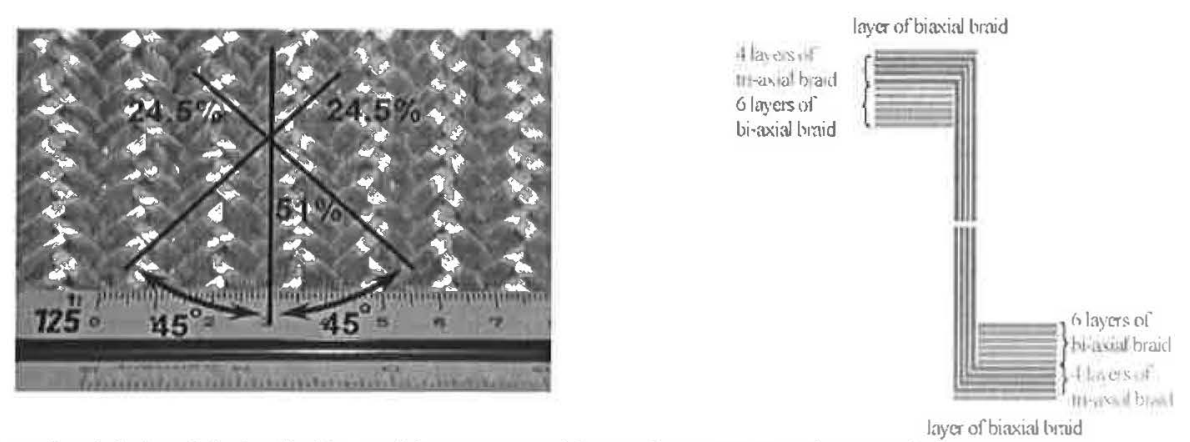

FIGURE 2. Triaxial dry fabric (left), and lay-up stacking of a GFRE column (right).

This lay-up was validated through Finite Element analysis, using I-DEASTM code, on a model of the composite column based on the measured material properties. The minimum stiffness requirement was attained; an axial compression stiffness of $24 \mathrm{GPa}$ was calculated.

A sensitivity study was also carried out to understand the effect of fibre orientation and volume fraction changes along the axis of compression. Several combinations of these two parameters were computed. According to these studies, the lay-up chosen presents the best compromise between stiffness and mechanical resistance, and it is also robust in performance with respect to manufacturing uncertainties on fiber orientation and volume fraction changes along the main axis.

A glass-fibre volume fraction $(\mathrm{V} f)$ of $45 \%$ was specified, with a dispersion not exceeding $\pm 2 \%$ and with a maximum void content of $1 \%$. Qualification tests on material samples at the beginning of the project, according to standard ISO 11667 , confirmed a V $f$ of $46.3 \%$, and a void content of $0.8 \%$.

\section{Mechanical Performance of the Composite Columns}

So as to monitor quality in the RTM production, $5 \%$ of the mass produced columns, taken randomly and regularly from the weekly production (approximately 2 columns over 40 produced per week), were subjected to a compression test and a shear test in a cantilevered configuration (Table 6.).

The compression test was aimed at checking structural integrity under $175 \%$ of the nominal load, to cover exceptional loading of the cryo-magnets during road transport, and at measuring the compression stiffness of the columns. The shear test was aimed at checking structural integrity under $130 \%$ of exceptional operating conditions of the cryomagnets (pressure tests and vacuum loads).

Failing to pass these tests would have implied segregation of the complete production of the week, identification of the cause of the failure and its resolution, and scraping or individual testing of these columns. This statistical approach allowed monitoring quality and detecting production drifts (due to tooling wear or other causes).

TABLE 6. Mechanical testing of composite columns.

\begin{tabular}{llll}
\hline Type of test & Load & Requirement & Note \\
\hline Compression & $175 \mathrm{kN}$ & $\begin{array}{l}\text { Elastic behaviour (residual deformation }<2 \% \\
\text { maximum displacement) } \\
\text { Achieved E }>17 \mathrm{GPa} \text {, dispersion within } \pm 5 \% \\
\text { throughout production. }\end{array}$ & $175 \%$ of magnet weight \\
Shear test & $40 \mathrm{kN}$ & $\begin{array}{l}\text { Elastic behaviour (residual deformation }<2 \% \\
\text { maximum displacement) }\end{array}$ & $130 \%$ of nominal load \\
\hline
\end{tabular}




\section{MANUFACTURE}

\section{RTM (Resin Transfer Moulding)}

After cutting them to the right length, the layers of dry fabric are first stacked in the external part of the specifically designed moulds (Figure 3, left). The bi-axial fabrics are added to form the two flanges. The internal part of the mould is then inserted; the mould is closed and sealed. Vacuum is pumped inside the mould down to a pressure of 10 mbar. Meanwhile the resin is poured into a dedicated pot, also sealed, in which the resin is preheated to condition the resin (reduce its viscosity and allow out-gassing of trapped air to limit the final void content in the part). The resin is then injected in the mould, under a pressure of 3 bar, in the pot, until the mould is full. At this stage, the mould, which integrates an electrical heater, is heated to a curing temperature of $125^{\circ} \mathrm{C}$, which is kept for $1 \mathrm{~h}$. The RTM cycle is fully automated and controlled by a dedicated controller which monitors pressures and vacuum, controls temperatures, and operates electro-valves to inject the resin (Figure 3, centre). All curing cycles (temperature versus time) are plotted, checked and archived to witness quality. After its cooling, the mould is opened and the composite part is easily released, thanks to a slightly conical shape $\left(0.5^{\circ}\right)$ of the mould and, consequently, of the part (Figure 3, right).

A systematic comparison of the weight of each column with the weight of the raw materials before RTM, could ensure that no fabric layer was left out and that the correct resin quantity had been injected.

One complete RTM process cycle, from preparation of the raw materials, until the release of the part and reconditioning of the equipment for the next processing cycle takes about 4 hours. 10 RTM sets (including spares for repair and maintenance), each with a dedicated controller, were needed to cover the production of some 4700 support posts over a period of about 3 years, employing about 7 full-time RTM operators, during normal working hours ( 1 shift, 5 days per week).

\section{Machining and Assembly of Heat Intercepts}

The RTM columns undergo final machining on $\mathrm{CNC}$ machines to achieve the required precision on the flanges, the bolting holes and the sliding slots (Figure 5.). The lower surface of the column, which serves as sliding surface on the vacuum vessel, is machined to a roughness of Ra2.5. Material in excess was foreseen for all surfaces needing machining, in order not to weaken the structure of the column. Specially designed jigs were used to hold the parts without deforming them.

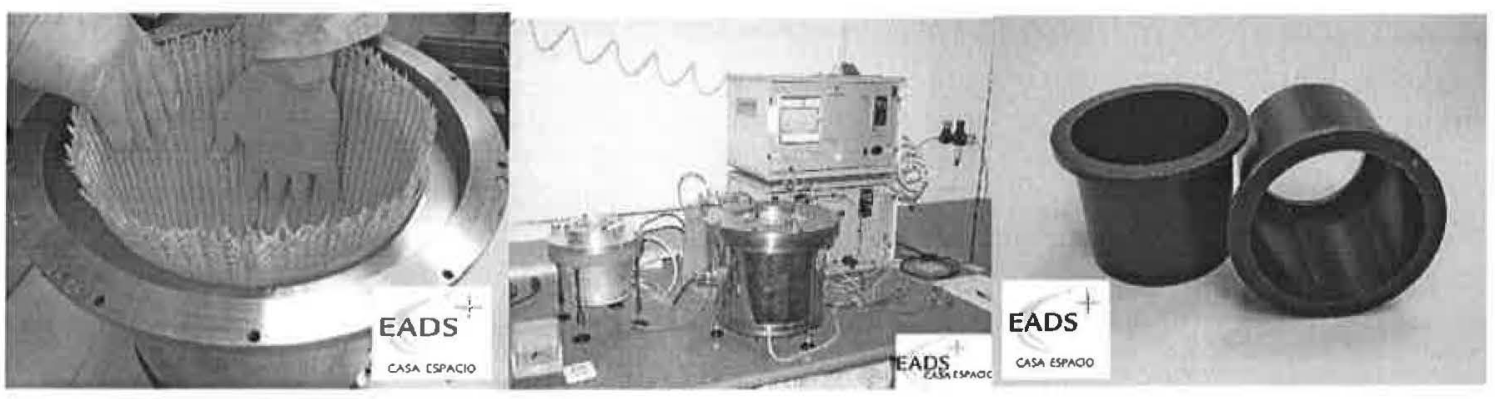

FIGURE 3. RTM process. Stacking of the dry fabrics in the external mould (left); an RTM work station (center); RTM columns after de-moulding (right). 


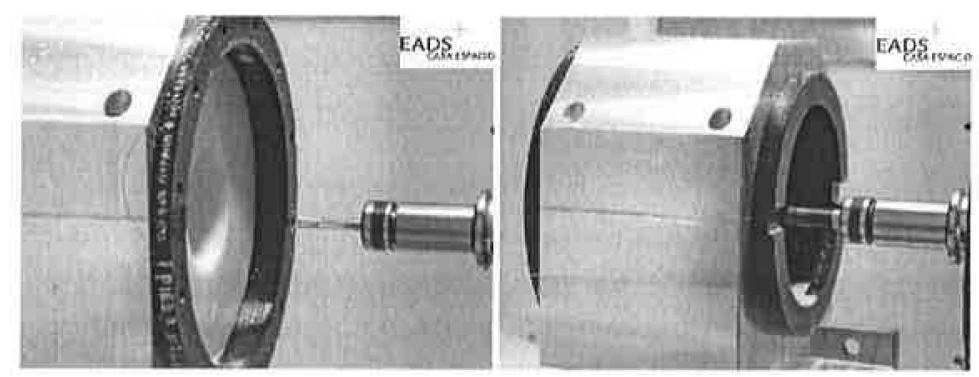

FIGURE 4. Machining of flanges by CNC. Boring of bolting holes (left) and machining of key slot (right).

Two heat intercepts, $10-\mathrm{mm}$ thick aluminium plates, are mounted externally to the composite column, to provide conduction-cooling through cryogenic lines in the cryostat. The C' line heat intercept, is obtained by casting aluminium (AISi8Cu3Fe -UNE38-267) over a steel tube insert (316L AISI) which is then welded to the C' cooling line of the cryostats. The $\mathrm{E}$ line heat intercept is made of an aluminium plate (series 6082) onto which two aluminium (series 6061) multi-foil flexible straps are welded. These straps, when welded to the cryostat cooling $\mathrm{E}$ line, provide efficient thermal extraction bridges while providing flexibility to cope with thermal contractions. The heat intercepts are glued to the composite column using EA9394, a two-part structural paste adhesive. The precision of the assembly is achieved using specially developed jigs (Fig. 5).

\section{Quality Assurance}

EADS-CASA covered the production of the support posts with the same quality assurance approach normally used for aerospace production.

All raw materials from external suppliers were systematically accompanied by conformity certificates and test reports. Specific incoming reception tests were made on the batches of epoxy resin to ascertain its quality: resin viscosity versus temperature and resin glass transition temperature $(\mathrm{Tg})$ were measured. All manufacturing processes were subjected to a strict quality control, critical parameters were measured and documented in order to detect process drifts. The RTM process, in particular, was followed by a strict quality control, with fully traceable records of all critical process parameters for all supports. Only 12 columns were discarded in the entire production due to non-conforming RTM processing, essentially when failing to control the correct curing cycle, or just because of failure in recording process data.

Dimensional controls on the columns and on the finished support posts were carried out on $100 \%$ of the production. Specific measuring and Go/No-go jigs were made for this purpose (Figure 7). Only 1 support was discarded due to an erroneous boring machining. The mechanical tests were carried out on universal testing machines with dedicated test tooling and data acquisition. The high reproducibility in compression stiffness, within the specified $\pm 5 \%$ band, is illustrated in Figure 7 for the dipole support posts. In only 4 cases the support stiffness was outside the band but no clear cause could be identified.

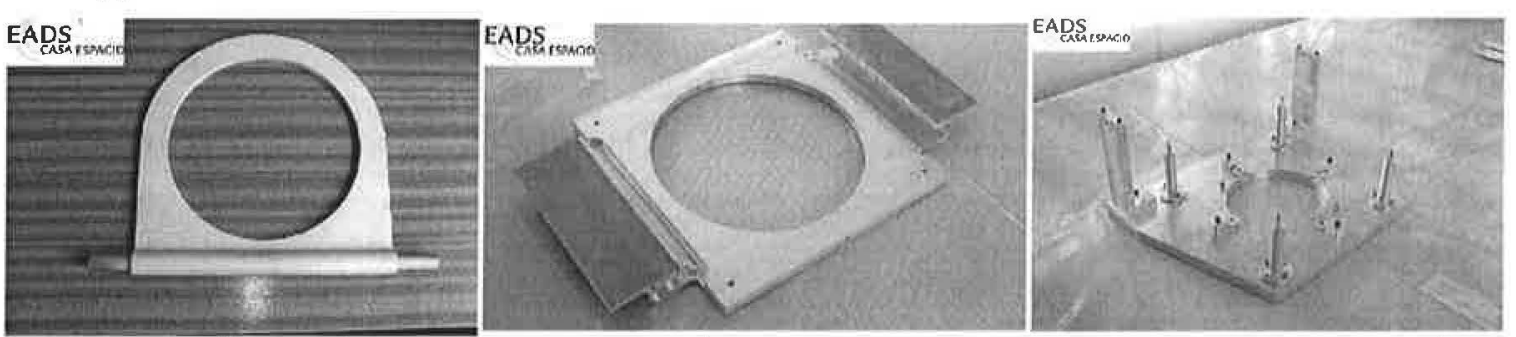

FIGURE 5. C' line heat intercept (left), E line heat intercept (center) and a support posts assembly jig (right) 


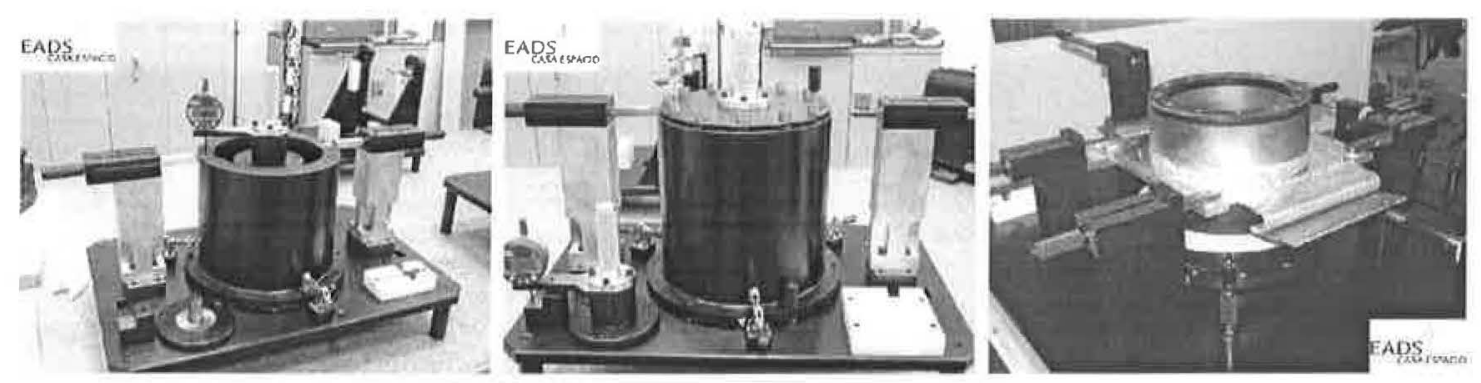

FIGURE 6. Dimensional measurement and Go/No-go control jigs
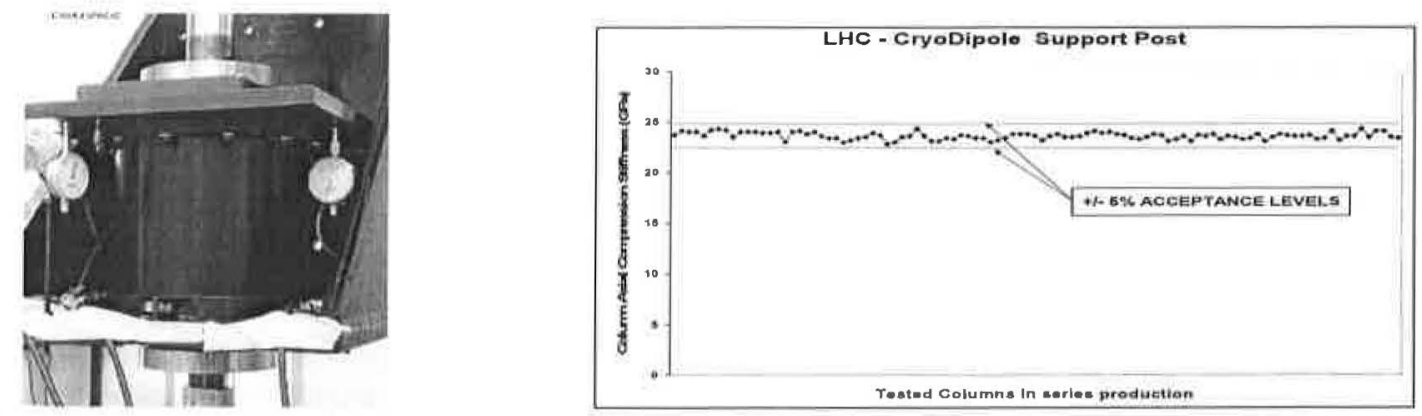

FIGURE 7. Compression test set-up (left), and compression stiffness results (right).

\section{CONCLUSIONS}

Some 4700 support posts of the LHC cryo-magnets were produced by the firm EADS CASA in about 3 years. The composite parts were manufactured in GFRE material, using RTM, chosen as being suitable for large-scale production, and highly automated thus guaranteeing high reproducibility in quality. The lay-up was designed to achieve a compression stiffness of more than $17 \mathrm{GPa}$, and was checked by calculation to be insensitive to manufacturing uncertainties on fiber orientation and volume fraction. A maximum dispersion $\pm 5 \%$ band was defined. The material was characterised by mechanical testing on samples at RT and at cryogenic temperature.

A strict QA plan was applied, including certification of raw materials, incoming inspections and tests on the resin system, follow-up and full traceability of manufacturing processes, in particular the RTM manufacture. Only 12 composite columns were discarded. Mechanical test were performed on $5 \%$ of the production to ensure satisfactory mechanical performance throughout the production. A compression stiffness of $23 \mathrm{GPa}$ was achieved and remained within the $\pm 5 \%$ dispersion band with the exception of few units.

Tight mechanical tolerances were achieved with a minimum of machining. The assembly of the composite columns with their heat intercepts was achieved by using assembly jigs and $100 \%$ of the functional dimensions were checked with go/no-go gauges.

\section{REFERENCES}

1. V. Parma et al. "Supporting systems from $293 \mathrm{~K}$ to $1.9 \mathrm{~K}$ for the Large Hadron Collider (LHC) cryomagnets", Advances in Cryogenic Engineering, Vol. 43-A (427-434).

2. V. Parma et al. "Geometry of the LHC Short Straight Sections before installation in the tunnel: resulting aperture, axis and BPM positionning", PAC'07, Albuquerque, New Mexico.

3. G. Vandoni et al. "Thermal performance of the supporting system for the Large Hadrn Collider (LHC) super-conducting magnets", Advances in Cryogenic Engineering, Vol. 45-A (795-802).

4. D.Cugnet et al. "Thermal conductivity of structural Glass/Fibre Epoxy composite as a function of fibre orientation", ICEC 19, 22-26 July 2002, Grenoble, France. 
